\title{
¿Es posible provocar la madurez del conflicto? \\ A propósito de la correspondencia entre Medófilo Medina y Timoleón Jiménez
}

\author{
Is it possible to provoke the maturity of the conflict? \\ Reflections around the mail exchange between \\ Medofilo Medina and Timoleon Jimenez
}

Adolfo León Atehortúa Cruz ${ }^{1}$

Resumen

A partir del intercambio epistolar entre Medófilo Medina y Timoleón Jiménez, el presente artículo debate los puntos centrales de la correspondencia aludida: la vigencia de la lucha armada, la concepción de dominación y dependencia y las vías de la democracia en Colombia. Finalmente, explora la madurez del conflicto armado en nuestro país y las posibilidades de una salida negociada con participación de la sociedad. Como conclusión, ofrece respuesta a dos preguntas: ¿Será posible una salida negociada que preserve la dignidad de los combatientes? Más aún, ¿será posible inducir esa salida desde la sociedad?

\section{Palabras clave}

Conflicto armado colombiano, solución concertada, democracia, sociedad civil.

\section{Abstract}

Within the context of the mail exchange between Medofilo Medina and Timoleon Jimenez, this article debates the central points of the mentioned mail letters: the current relevance of the armed struggle, the conception of dominance and dependence and the pathways towards democracy in Colombia. Finally, the article explores the maturity of the armed conflict in our country and the possibilities of a concerted way out with the participation of civil society. As a conclusion, answers to the following two questions are offered: Will it be possible to come up with a concerted way out that preserves the dignity of the fighting people involved? Even more, will this way out be possible from the civil society?

Key words

Colombian armed conflict, concerted way out, democracy, civil society.

Artículo recibido el 15 Febrero de 2012 y aprobado el 30 Marzo de 2012

1 Doctor en Ciencias Sociales del École Des Hautes Etudes en Sciences Sociales. París, Francia. Profesor de la Universidad Pedagógica Nacional. Decano de la Facultad de Humanidades de la Universidad Pedagógica Nacional. adolfoatehortua@ cable.net.co 
En julio del año pasado, el profesor Medófilo Medina dirigió a Alfonso Cano, entonces máximo dirigente de las FARC, una exigente y reflexiva misiva en la que cuestionaba la continuidad del conflicto armado en Colombia y lo invitaba a tomar un camino diferente al transitado por su organización durante más de cuarenta años.

Si bien no desconozco que el origen y el desarrollo de los conflictos sociales obedecen a razones objetivas y a causas estructurales -dijo entonces el profesor Medina-, por otra parte subrayo el papel de las decisiones o de las escogencias entre alternativas políticas que llevan a cabo las partes en el conflicto. (Medina, 2011)

Alfonso Cano no tuvo la oportunidad de responder. Tal como dijo el arzobispo de Cali, monseñor Darío de Jesús Monsalve, "sin agotar el marco ético de la captura como objetivo legal", fue muerto "en condiciones de desproporción absoluta, herido, ciego y solo"'.

Le correspondió entonces a Timoleón Jiménez, Timochenko, continuar el intercambio epistolar con una carta que, a diferencia de aquella de Medófilo, no fue suficientemente reproducida por los medios, o generó tan solo la interpretación parcial bajo el fantasma de El Caguán².

\section{Circunstancias históricas de la lucha armada}

Probablemente el punto más importante en el debate epistolar entre el profesor Medófilo Medina y el comandante de las FARC guarda relación con la continuidad y vigencia de la lucha armada. Por supuesto, el documento del profesor Medina sustenta cada uno de sus criterios. Sin embargo, es importante destacar algunos puntos e interrogantes con los cuales cuestiona la prolongación de la lucha armada al indagar su devenir y actualidad:

1. Para las FARC, la lucha armada fue una respuesta popular a la violencia de latifundistas y ganaderos amparados por un régimen

1 "A Cano no le preservaron la vida". Semana, diciembre 1 de 2011.

2 El texto completo de la misiva puede consultarse, igualmente, en http://www.razonpublica.com/ político antidemocrático y excluyente. La premisa es aceptada por Medina, a condición de seguirla con distancia crítica en su desarrollo: Sin duda en 1949 y en algunas regiones donde venían consolidándose los movimientos de colonos y campesinos, resultó inevitable organizar la autodefensa armada, no ya en defensa de la tierra sino de la vida misma. Pero ya en la primera pausa de "La Violencia" en 1953, había motivos para plantearse la reorganización de un movimiento agrario que, por ejemplo en el sur del Tolima, venía trabajando con vigor desde mediados de los años treinta. No obstante, dicha reorganización del movimiento campesino no ocurrió. Ni en ese momento ni poco después con los sucesos de Marquetalia, fue posible adelantar una tarea de tal índole. La política de "combinación de las formas de lucha", adoptada en 1966 por el X Congreso del Partido Comunista, intentó compatibilizar en una misma matriz política y de manera simultánea un movimiento militar insurgente con un movimiento social que tenía sus propios ritmos y demandaba independencia política y organizativa.

2. Sumapaz y Viotá constituyen un "modelo alternativo" en el cual la guerra terminó sin pasar por una derrota de los combatientes. Una experiencia que no pudo ser replicada.

3. En lugar de ajustar la política a la primacía de los escenarios urbanos y adecuarla a la cultura política que había reflejado el Paro Cívico Nacional de 1977, el camino escogido por la izquierda fue "insistir en las mismas estrategias de antes y darles la espalda a las nuevas realidades".

4. Dado lo anterior, es necesario conocer, objetivamente, la argumentación de las FARC con respecto al por qué de la guerra y sopesar su visión del país actual y sus propuestas hacia el futuro.

Finalmente, dos preguntas para la reflexión: “Cuáles son los beneficios que esta lucha abnegada de tres generaciones de hombres y mujeres guerrilleros le han traído a Colombia? ¿Cuáles grupos de 
trabajadores rurales o urbanos han logrado conquistas sociales duraderas por obra de las FARC durante este medio siglo?"

Como corolario, sostiene el profesor Medina: "Uribe se gestó en el contexto del con razón llamado 'síndrome del Caguán', un fenómeno político - emocional que arrastró a la mayoría de la opinión y la puso en manos de la extrema derecha”. Así mismo, la parapolítica se convirtió en el mecanismo más eficaz de reclutamiento de un nuevo personal político con los resultados que todos conocemos.

La respuesta de Timoleón Jiménez, escrita en diciembre de 2011, ha sido respetuosa, franca y, si se quiere, con tonalidades académicas. "Pulcra" en sentido literario, la definió Maria Jimena Duzán, para quien la nueva retórica del comandante de las FARC "se construye sobre premisas interesantes y novedosas que demuestran que detrás de este jefe guerrillero hay un hombre que se preocupa por leer en medio de la guerra"3.

Los argumentos de Timoleón Jiménez ocupan un grueso párrafo que es útil transcribir en extenso:

Ni en ese Programa Agrario, ni en ningún documento posterior de las FARC hasta la fecha de hoy, se ha planteado jamás que como organización político militar nuestra meta sea la toma del poder tras derrotar en una guerra de posiciones al Ejército colombiano, como se repite una y otra vez por todos aquellos que insisten en señalarnos la imposibilidad de ese objetivo. Desde nuestro nacimiento las FARC hemos concebido el acceso al poder como una cuestión de multitudes en agitación y movimiento. Así como con la táctica de la combinación de las formas de lucha definimos que no desdeñamos ninguna de las vías que las clases dominantes nos permitan u obliguen a emplear.

Si bien puede pensarse que el debate a los postulados de la carta corresponde al profesor Medófilo Medina, es posible adelantar algunas inquietudes:

En América Latina las revoluciones contemporáneas han sido obra de jóvenes; creación, desarrollo y conclusión de una sola generación. Lo fueron

3 “Timochenko, el escritor". Semana, enero 14 de 2012. las revoluciones cubana y sandinista. Fidel Castro cumplía 32 años y Ernesto Guevara 30 al arribar triunfantes a La Habana; Daniel Ortega 33 al momento de derrocar a Somoza.

Los movimientos sociales se concatenan, se unen, se relacionan, pero no se heredan, no se trasladan. Menos aún si se trata de la lucha armada. Si la generación que se levanta en armas no logra el triunfo antes de envejecer, la revolución fracasa o se degrada. El Frente Sandinista tardó 19 años en alcanzar la victoria desde su fundación por Carlos Fonseca; el Movimiento 26 de julio menos de 6 años luego del asalto al Cuartel Moncada en Cuba.

La lucha armada revolucionaria es hija de la dominación colonial con cuerpo presente, como ocurrió en las independencias americanas: de las ocupaciones e invasiones extranjeras, como sucedió en China o Vietnam o como se expresó en la resistencia contra Hitler en Europa Central; de las dictaduras sangrientas y de la más aberrante negación de libertad, como en la Rusia zarista, la Cuba de Batista o la Nicaragua de Somoza. Sin embargo, pierde su vigencia histórica cuando esas condiciones que la propician no existen o desaparecen, dijo Ernesto Guevara en su “Obra Revolucionaria”(1967). Su propia experiencia en Bolivia o lo sucedido en El Salvador y Guatemala en los años ochenta así lo corroboran. En estos últimos países, el triunfo revolucionario armado se dificultó cuando las dictaduras militares abrieron paso a gobiernos elegidos.

En otros casos, a pesar de la innegable presencia de las circunstancias referidas, la lucha política sin empleo de las armas hizo posible una transformación revolucionaria, como en la India de Gandhi, en el Irán de los ayatollahs, o en la experiencia sudafricana de Mandela.

Cuando la lucha armada revolucionaria tiene vigencia, arrastra masas tras ella. Así ocurrió en Santa Clara, con la presencia de Guevara, y en Estelí, en 1978 y principios de 1979, cuando una reducida presencia sandinista desencadenó insurrecciones populares, no previstas incluso por la guerrilla. Por el contrario, grandes cantidades de población la rechazan cuando pierde su carácter de alternativa 
real o cuando resulta ineficaz o contraproducente para alcanzar objetivos y reformas.

La lucha armada revolucionaria no puede ser indefinida, no puede perpetuarse en el tiempo; triunfa, cae derrotada, negocia transformándose o se transforma degradándose. Las experiencias de uno u otro evento podrían citarse con lujo de detalles en el transcurso de la historia universal.

El fin de la Guerra Fría y los nuevos movimientos sociales construyen escenarios diferentes que en nuestra realidad cotidiana se revelan con claridad expresa y se ofrecen para su comprensión con nuevas tácticas y estrategias de acción. Los brotes juveniles recientes en todo el mundo, el disímil levantamiento de los pueblos árabes, el movimiento "okupa", los "indignados", la presencia beligerante de "Anonymous" en la red, constituyen nuevas experiencias de lucha que deben observarse con una nueva óptica. Desde el punto de vista político podría ser incluso una obligación de la estrategia.

\section{Dominación y dependencia}

Otro aspecto importante en el cruce de correspondencia hace referencia a la democracia y la construcción de sus reglas. El comandante de las FARC desconfía de las realidades y bondades de la democracia en Colombia, de las reglas en torno a las cuales se construye el ejercicio democrático y la participación ciudadana.

La política como tal, en este país y en la mayoría de las economías de mercado, ha perdido por completo su esencia. No se llega al poder para cumplir un determinado programa. Se llega para ejecutar las directrices emanadas de los grandes poderes internacionales. Las economías y los planes de desarrollo nacionales y locales están condenados a cumplir con el libreto del FMI, el Banco Mundial y la OMC, entre otras instituciones. Cada país y provincia tienen ya su destino fijado en una cumbre previa. Ningún gobierno puede salirse del guión establecido.

El "escepticismo fundado en la experiencia" es también otro de sus argumentos:

"Nuestros Estados se hallan condenados a desempeñar un rol subordinado en el entorno de los intereses del gran capital trasnacional”.
Valga hacer algunas anotaciones para fijar posición frente al debate:

El desarrollo de las sociedades no es tan simple para definirlo en conciliábulos o en juntas de banqueros. Existen dictámenes internacionales, es cierto, pero se aplican a raja tabla allí donde las correlaciones de fuerza del juego político lo permiten o en donde las coyunturas lo favorecen y facilitan. Las relaciones internacionales no son unidireccionales ni verticales, son bilaterales, multipolares.

La sociedad es considerada un tejido complejo de relaciones humanas cuya interacción se dirige a fines conforme a reglas relativamente establecidas, pero con capacidad para actuar sobre sí misma y engendrar su porvenir y hasta su memoria. En este sentido, no es una simple suma de individuos sino un sistema formado por su asociación interdependiente, política y cultural, cuyos roles construyen y representan una realidad con características y significados propios.

Las recientes experiencias latinoamericanas son un ejemplo de escenarios y roles cambiantes, apreciación suscrita por el mismo Medófilo Medina en su misiva original. El Brasil de Cardozo no fue el mismo de Lula; el discurso y la práctica de los Kirchner no ha sido el mismo de Menem; Correa, Morales y Ortega han esgrimido las consignas del ALBA a pesar de las contradicciones y apremios locales de sus propias burguesías; sin abandonar la economía de mercado ni el papel del petróleo en los designios financieros nacionales, el gobierno de Chávez representa una posición política diferente a la que posee su principal comprador de crudo. En medio de asfixias económicas, no pocos gobiernos levantan la dignidad de sus pueblos frente a las presiones monetarias.

La historia reciente de Colombia ofrece también episodios interesantes. Carlos Lleras Restrepo asumió, de cierta forma, una postura independiente y crítica frente a imperiosas demandas de política económica realizadas por el Fondo Monetario Internacional. En concreto, cuando en 1966 el FMI, la AID y el BIRF, exigieron la devaluación del peso a fin de incrementar las exportaciones y nivelar a su favor la balanza de pagos, el presidente Lleras se opuso 
con energía y demostró cómo, por el contrario, una medida de tal índole significaría el suicidio político de su gobierno con la bancarrota del equilibrio estructural de los pagos (Atehortúa y Rojas, 2005).

Desde luego, no se desconoce la alta estima y confianza del presidente Lindon Johnson hacia Lleras, ni el hecho de que este último hubiese trabajado estrechamente con funcionarios norteamericanos y empleado un equipo de economistas de Harvard para ayudar en el diseño de sus políticas económicas(Randall, 1997, 276). Lo que se quiere subrayar, a título de ejemplo, son los campos de acción en que se mueven los equilibrios gubernamentales y sus políticas internacionales, que no van en un solo sentido y no se someten en todos los asuntos a la dependencia extrema.

Con relación al Plan Colombia, diversas investigaciones han demostrado que esta no fue una estrategia claramente definida desde el principio, ni tampoco el producto de una voluntad deliberada y homogénea. Ella se fue perfilando paulatinamente al calor de los acontecimientos en Colombia y de los debates en Estados Unidos. El Plan se construyó en la negociación de intereses y posiciones entre el Departamento de Estado, el Congreso norteamericano, algunas ONG y el gobierno colombiano. La multiplicidad de actores, intereses y escenarios que entran en juego a la hora de definir una política, ganan aquí una expresión contundente.

En fin, volveríamos al viejo debate que las concepciones sobre dominación y dependencia suscitaron en los años sesenta en América Latina. Por supuesto, no se acoge el extremo de considerar estas teorías "simplistas" o "mecanicistas"; sus expositores buscaban explicar y transformar las condiciones de nuestros países frente a la expansión mundial del capital y sus poderes hegemónicos. Pero, aún así, sus esquemas no reprodujeron una imposición de afuera hacia adentro, sino una relación de subordinación entre los procesos económicos y políticos operados en los países periféricos con respecto a los centrales, siempre y cuando las condiciones se posibilitaran bajo los diferentes espectros de cada estructura interna.

Las concepciones sobre dominación y dependencia caben en la categoría de aquellas que Immanuel
Wallerstein invita a "impensar" para el derrumbe esperado de las barreras intelectuales y la construcción de paradigmas que permitan la comprensión de nuestras realidades(Wallerstein, 2003, 3).

\section{Democracia y democratización}

A partir de la experiencia vivida por la Unión Patriótica, Medófilo Medina había expresado en su carta:

El intento de sentarse en dos sillas a un mismo tiempo fue una decisión inevitablemente utópicocatastrófica. No soy tan ingenuo para pensar que los exterminadores de la UP se hubieran convertido en palomas de la paz o en defensores de Derechos Humanos ante la decisión de renuncia a las armas por parte de los insurgentes. Sin embargo considero que amplios sectores políticos y corporativos del país se hubieran constituido en dique de contención frente a esa alianza siniestra. Guiados por la ética, o aún por pautas mecánicas del principio de justicia, hay fuerzas de opinión considerables que en casos semejantes han jugado en defensa de quienes optan por dejar las armas.

La respuesta de Timoleón Jiménez es aguda e incrédula:

Lo que ha sufrido nuestro país durante décadas es la siniestra práctica fascista de seguridad nacional con traje de democracia.

[...] ¿ ¿Usted de veras cree que tiene alguna presentación decir que el genocidio contra la Unión Patriótica hubiera sido evitado por la reacción ética de fuerzas considerables de opinión surgidas como reacción del abandono de las armas por nosotros?

En gracia de discusión y con las cifras reales como testigo, podría aceptarse en parte su apelación. Pero no puede olvidarse el contexto histórico. El paramilitarismo surgió como proyecto apoyado en el éxito de la droga y actuó en consonancia con la violencia para construir su propio poder regional y nacional. El exterminio de la Unión Patriótica y de centenares de luchadores por la democracia no se ejecutó por fuera de aquel fenómeno. La guerra sucia en Colombia, a diferencia del Cono Sur en donde fue agenciada de manera directa por las Fuerzas 
Armadas, contó con la decidida participación de narcotraficantes que, a partir del MAS, pasando por las "autodefensas" y las "Convivir", hasta la parapolítica, fueron cooptadas como política de Estado o recibieron el apoyo de sectores empresariales, latifundistas y ganaderos, políticos, militares y gubernamentales.

Sin embargo, es preciso también cierto análisis teórico sobre las potencialidades de la democracia.

¿Qué se entiende por democracia? Obviamente, diferentes cosas en diferentes lugares. En contraposición a la gerontocracia u oligarquía, la democracia significa mucho más que un aclamado juego de "carreras abiertas a todos los talentos". En oposición a la autocracia, la democracia significa esencialmente la participación de sectores autónomos dentro de la sociedad, sean económicos, sociales, étnicos o religiosos. Con la democracia, como con otras categorías sociales, la clase de contraste es tanto histórica como socialmente variable.

Para Giovanni Sartori, la democracia es un sistema político llamado a resolver problemas de ejercicio del poder, pero también un principio de legitimidad y, ante todo, un ideal(Sartori, 1994). Para Norberto Bobbio, en la teoría política contemporánea predominante en los países de tradición democrático-liberal, las definiciones de democracia tienden a resolverse y a agotarse en un elenco más o menos amplio de "reglas de juego" o "procedimientos universales"(Bobbio, 1981, 441). Entre ellos destaca la existencia de instituciones con dirigentes elegidos como la jefatura de Estado o los entes de la administración local: la elección por el pueblo del máximo órgano político, el sufragio universal, la participación en las decisiones políticas, y el derecho a expresar su opinión formada libremente.

Aunque en las nacientes democracias el término es utilizado como referencia a una contienda competitiva por los votos de la gente, es pertinente considerar dos aspectos de importancia en el análisis:

En primer lugar, parece claro que los nuevos movimientos democráticos necesitan reflexionar acerca de sus vínculos con esa tradición y sobre la connotación del término en la teoría política de occidente: ¿Es la democracia tan sólo una contienda competitiva por los votos de la gente?
En segundo lugar, es importante mirar la democracia como un estado final, como el resultado de un proceso colectivo, que no es otro que la propia democratización. Por esa razón, para las sociedades en transición, preguntas acerca de cómo traspasar de un momento a otro en dicho proceso, son de vital importancia. Tal vez algunas preguntas de estrategia micro-política no admitan generalización útil y deban dejarse a la práctica concreta de los políticos. Pero aún eso es dudoso. Ningún caso es completamente sui generis y aún las generalizaciones limitadas pueden ser políticamente invaluables para coyunturas históricas particulares.

En todo caso, existe un considerable cuerpo de experiencias concernientes a lo que una vez fue llamado "precondiciones de la democracia". Se trata de ciertas condiciones político-legales, socio-culturales, económicas, internacionales que, si no son totalmente decisivas, constituyen, por lo menos, las bases sólidas para la democratización de una unidad política particular. Esto es muy valioso en el presente momento histórico mundial: vale la pena recapitular todos los análisis que sobre la democracia occidental se han realizado; vale la pena reflexionar sobre aquello que nos falta aún por descubrir. Aquí vale de nuevo invocar a Wallerstein: impensar las ciencias sociales.

Dentro de la teoría política, se han desarrollado tres características de la democracia más allá del antagonismo y de la competencia electoral: democracia como fortaleza, deliberación y participación. En política comparada, se ha adquirido una clara imagen de los diferentes y alternativos caminos hacia la democracia, de sus prerrequisitos sociales, económicos y políticos, y de las consecuencias de cada uno de ellos. Dentro de la sociología política se han apreciado los sistemas de valores y las prácticas culturales que sustentan y son sustentadas por formas políticas democráticas de diferentes órdenes.

En fin, de orígenes tan diversos como la economía política y las relaciones internacionales ha sido recordada la imperfección, la negociabilidad y permeabilidad de los límites de la política y, por consiguiente, del rango y del alcance de las formas políticas democráticas. Así, es importante, al discutir 
sobre la democratización, que no fijemos nuestra atención exclusivamente en las instituciones y procesos de gobierno. Debemos reflexionar, ante todo, sobre los problemas, conflictos y consecuencias que aparecen en torno a los procesos democráticos; al alcance sobre los sujetos a los cuales son aplicados; a la incorporación de algunos grupos y a la exclusión de otros como recurso para las instituciones así constituidas por estas prácticas y procedimientos.

Un nuevo grupo de interrogantes podría volver a las preguntas más comunes en relación con el Estado, su construcción histórica, sus correlaciones internas de fuerza y su propia dinámica. Pero no desde el Estado. Deberían atender, en el mejor sentido, la historicidad misma de las instituciones para designar no lo instituido sino lo instituyente (Touraine, 1987).

Digámoslo de otra forma: si bien aceptamos que no ha sido posible fundar una democracia desde la ética de la opinión, es claro que ello es menos posible bajo la lógica de las armas. Por el contrario, el ruido de estas, desde uno u otro ángulo, termina destrozando a la opinión, manipulándola, coartándola; atenta contra la misma democracia, pervirtiéndola.

La participación en la construcción permanente de la democracia no puede hacerse con armas en la mano. La democratización es, esencialmente, una noción política participativa cuya fortaleza se nutre con la legitimidad y se vive en la legalidad. Ella renueva o conduce a la introducción de elementos de desarrollo, de participación y de control popular dentro de la estructura social y de los procesos de dirección política o gobierno.

La Constitución de 1991 y uno de sus más importantes logros, la tutela, tiene relación con la lucha popular expresada de diversas formas; pero se concreta con la presencia directa en los cuerpos constitucionales de quienes, tras abandonar las armas, asumieron las formas de participación legal y tomaron parte en la correspondiente redacción de los artículos.

Finalmente, al lado de la democratización, es necesario asumir algunas definiciones de lo que se considera como régimen político. Y para ello, un aporte concreto es el que ofrece Lucio Levi: "Por régimen político se entiende el conjunto de las instituciones que regulan la lucha por el poder y el ejercicio del poder y de los valores que animan la vida de tales instituciones"(Levi citado en Bobbio, 1409).

Sin embargo, es pertinente agregar algunas precisiones. Todo régimen político debe entenderse como un sistema histórico, término que aludiría a dos condiciones: 1. Conjunto integrado, es decir, compuesto de partes relacionadas entre sí, y 2. unidad con historia, vale decir, génesis, evolución, transformación.

El régimen político incluye instituciones que constituyen la estructura organizativa del poder político: Estado, partidos, normas y procedimientos que tienen como objeto garantizar su propia existencia en el tiempo. Pero comprende igualmente el sistema de relaciones y comunicación que vincula a los miembros de la sociedad: individuos, grupos y clases sociales, con el poder político ${ }^{4}$.

Por consiguiente, la estructura del régimen, es decir, su forma, modo de organización y sistema de definición de las correlaciones de fuerza de los grupos sociales y/o políticos, condiciona el modo de formación de la voluntad política y, en consecuencia, como advierte Levi, "el empleo de ciertas instituciones", de "determinados medios para la formación de las decisiones políticas..." (Levi citado en Bobbio, 1409).

No se puede renunciar a la posibilidad de construir la democracia cuando es este un proceso que puede involucrarnos a todos.

\section{La madurez del conflicto}

Para evitar caer en la tentación de los debates, puede ser más útil retornar a algunas anotaciones que en torno a la madurez de los conflictos hizo Christopher Mitchell, un emérito analista de la Universidad de Londres:

Según Mitchell, la negociación de un conflicto es producto de circunstancias diversas, condicionadas por los procesos, el contexto y el tiempo, pero

4 En el sistema conceptual de Gramsci, por ejemplo, el régimen político estaría determinado por el tipo de relaciones y diferencias presentes en el juego de dos categorías: sociedad civil y Estado. 
también por la actitud de las partes y el importante papel de la influencia externa. Se considera que los conflictos "están a punto" o que han alcanzado la madurez suficiente para someterse a un proceso de mediación o negociación, cuando se configuran los siguientes requisitos:

1. Cuando los conflictos son extremadamente complejos y prolongados en el tiempo. Ninguna de las partes logra una victoria definitiva y los costos de todo tipo se incrementan sin lograr una escalada decisiva o una salida airosa.

2. Cuando los esfuerzos por administrar el conflicto permiten vislumbrar la amenaza de un desastre o prometen lesionar a los adversarios estancados.

3. Cuando ninguno de los contradictores está en disposición o capacidad de soportar los costos crecientes de una escalada del conflicto.

4. Cuando las partes del conflicto están dispuestas a romper el costoso estancamiento acogiendo un objetivo secundario que depare dignidad, e implicándose en alguna comunicación o contacto (Mitchell, 1997) 5.

Mitchell ha recopilado y analizado estos cuatro modelos destacando cómo aprenden los líderes: por medio del sufrimiento, por medio del pensamiento racional y de la previsión y/o aplicando teorías. De esta manera se involucran en procesos de renuncia, "salvando todo lo salvable" y tratando de salir, lo más rápidamente posible, de una política evidentemente fallida.

Para Mitchell, la madurez del conflicto se percibe como una etapa en la que es posible conseguir un cambio en la mentalidad de las partes. En la que es factible transformar la idea de la victoria absoluta por aquella de la conciliación con pérdidas razonables. En esta etapa se señala el papel que juegan los factores sistémicos o estructurales y los relacionados con la toma de decisiones, es decir, las dimensiones subjetivas de la madurez. En su opinión, compartida por otros analistas como Zartman (1982) o Edmead

5 Christopher Mitchell. Evitando daños: Reflexiones sobre la situación de madurez en un conflicto. Estudios Internacionales, Guatemala, Vol. 8, $n^{0} 15$. Puede observarse en http://www.gernikagogoratuz.org/
(1971)6, son tan importantes las percepciones y las decisiones de los actores y sus líderes, como las mismas condiciones estructurales y sistémicas, pues en última instancia serán los actores y sus líderes quienes interpretarán dichas condiciones y decidirán, en parte, la suerte de los procesos. En otras palabras, es también esta la teoría de los actores planteada por Alain Touraine: además de ubicar al actor en la historia, indagar sobre la producción de situaciones históricas por actores ${ }^{7}$.

\section{Realidad vs. percepción}

En este último espejo se ubica la carta del profesor Medófilo Medina, susceptible de ser apreciada como un gran aporte para la paz en nuestro país. Su carta es, al mismo tiempo, un ejemplo claro de diplomacia civil o "de terreno", como la llamara Reychler, basado en la experiencia de los conflictos africanos cuya resolución se abordó en los años setenta: aquella que se ejerce con un clima de confianza y provoca sinergias de aproximaciones (Reychler, 1997: 32-35).

Medina ha puesto a pensar a los actores, a la elite del país, al mundo académico, a muchos ciudadanos en Colombia. La Universidad no puede ser ajena a este intento. El intercambio epistolar entre él y Timoleón Jiménez nos permite a los analistas examinar también la madurez de nuestro conflicto. En tal sentido, la madurez objetiva que permitiría prefigurar los cuatro escenarios que refiere Mitchell, es mucho más clara que las valoraciones subjetivas de los actores.

Las partes en conflicto se muestran reticentes a abandonar su lucha, o al menos, a buscar un acuerdo negociado, incluso cuando las condiciones parecen ser enormemente desfavorables como para mantener un esfuerzo costoso para lograr objetivos que parecen cada vez más y más inalcanzables (Mitchell, 1997).

Esto opera en contra de la percepción, un fenómeno que autores como Zartman (Zartman, 1982) han llamado el "efecto trampa": los hombres aman

\footnotetext{
6 Edmead. E. (1971) Analysis and prediction in international mediation New York, Nitar.

7 Alain Touraine. op. cit.
} 
hasta la muerte aquello por lo que han sufrido. Y en esa lógica, las partes en conflicto, los actores, encuentran absurdo u observan como traición una vuelta a la negociación. Se enredan por orgullo en los callejones sin salida que la violencia ofrece.

Cuanto mayor es el sufrimiento, mayor es la necesidad de avanzar a la victoria y menor la posibilidad de rendirse. En el Palacio de Justicia, precisamente, este efecto impidió un acuerdo posible en el segundo día de la confrontación cuando ya todo estaba decidido. Ni Andrés Almarales cedió a la liberación de los últimos rehenes, ni las Fuerzas Militares permitieron en el momento justo el ingreso de la Cruz Roja. Cayeron en la trampa de la destrucción armada sin tomar en cuenta a los civiles que estaban de por medio.

¿Cuándo se produce, en este modelo de situaciones, un clima de madurez para el conflicto? La respuesta, una vez más, la ofrece Mitchell:

En un conflicto prolongado los líderes pasan por una serie de etapas distintas en su proceso decisorio. La primera de ellas se orienta hacia el logro de recompensas potenciales. La segunda justifica los recursos empleados con nuevos compromisos. En las dos últimas, cobran relevancia los objetivos de provocar daño al adversario y de minimizar las pérdidas globales; se transforman los objetivos hasta el punto de parecer más reales, se espían las culpas y se reivindican logros que una observación juiciosa no asimilaría como tales. Finalmente se reconoce el agotamiento de los recursos y se busca una salida. (Mitchell, 1997)

Los escritos de Timoleón Jiménez traslucen este momento en algunos de sus apartes. Un tránsito de la tercera a la cuarta etapa, tal como lo percibe María Jimena Duzán:

Tuve la impresión de que quien escribía esa carta era un hombre adolorido por la guerra, hastiado por la guerra. Y por un momento pensé que un ser así, capaz de hacernos sentir ese dolor a través de una carta, tiene que ser un hombre que no está pensando en morir, sino en vivir (Duzán, 2012).

La superación no es fácil. No pocas retóricas caen en la misma trampa sin alcanzar la madurez que se precisa. José Félix Lafaurie, actual presidente de Fedegan, lo ejemplifica con una sola frase: "No se puede volver a la disyuntiva entre derrotar la criminalidad o abrir la puerta de la negociación"(Lafaurie, 2012). Se enreda en el efecto, desconoce la evolución de los conflictos, las variantes condiciones en que se desarrollan y, sobre todo, sus costos, el balance de los ahorros en economía y sangre.

Las violencias, cuando son un rasgo estructural de la evolución socio-política del país, no pueden aparecer como lo más definitorio de ninguna coyuntura. Como en general la violencia es la manifestación de conflictos agudos en distintas áreas de la actividad humana, entonces lo específico de la coyuntura está dado, más bien, por formas particulares de las relaciones sociales cuyas contradicciones buscan resolverse a través de la violencia. Por consiguiente, lo definitorio de la coyuntura no es la violencia (o las violencias) en sí misma(s), sino determinadas y específicas formas conflictivas de las relaciones sociales.

Por fortuna, desde el Estado parece construirse una lógica de la re-evaluación en medio de dificultades y retrocesos. Dirigentes orgánicos, como dijera Gramsci, han coincidido al señalar que las llaves de la negociación no se han botado, y no han descartado ni el carácter secreto de una conversación inicial, ni un eventual cese al fuego con verificación internacional8.

\section{Tres opciones}

En este sentido, tres ofertas se presentan hoy en forma clara ante el país: una, la supuesta disyuntiva de incrementar la guerra para buscar una victoria o negociar con una guerrilla derrotada militar y políticamente; otra, sobrevivir y resistir en una guerra que aborrece la inmensa mayoría de los colombianos y que traspasa las fronteras del crimen sin lógica revolucionaria; y finalmente, buscar alternativas inmediatas a la guerra para disminuir sus costos con un acuerdo mínimo.

La última de las alternativas, desde luego, se mueve en un espacio concreto: o la sociedad cae como víctima en una guerra costosa que solo busca

8 El Tiempo, enero 15 de 2012. 
el posicionamiento o la rendición de los actores frente a una eventual negociación, o exige y acelera la posibilidad de esa negociación para evitar los costos de una prolongación bélica infructuosa que terminará, de todos modos y después de muchas otras muertes, en una negociación necesaria.

La sociedad no puede permanecer indefinidamente atada a guerra que, en el fondo, no busca en el presente otra cosa diferente a la de mejorar la posición negociadora de una de las partes y la rendición de otra, propiciando el desangre de la nación. El resultado final de lo acaecido en el Palacio de Justicia es la mejor muestra de lo que puede ser la perspectiva bajo el "efecto trampa" de que nos hablan los expertos en resolución de conflictos ya citados. Por tanto, la sociedad debe salir al paso y construir sus propias exigencias, fabricar sus propuestas y salidas.

Indudablemente no es ya el modelo M-19, salvadoreño o guatemalteco de negociación el que se impone. Menos aún, el esquema frustrado en El Caguán. La acción mediadora basada en los ciudadanos y sus organizaciones ha jugado en diversos conflictos un papel renovador, fresco y efectivo. John McDonald, fundador del Institute for Multi-Track Diplomacy, distingue nueve actores que pueden asumir con éxito este tipo de trabajo $^{9}$ : gobiernos, organizaciones profesionales, comunidad de negocios, iglesias, medios de comunicación, ciudadanos privados, institutos de formación y educación, activistas y fundaciones. La Universidad, desde luego, se cuenta entre ellos.

La etapa de madurez en los conflictos, en conclusión, puede ser inducida y propuesta con la participación de terceros. Más aún, por exigencia de la sociedad. Allí es donde se ubica nuestro papel: producir la madurez del conflicto para que los actores asuman la negociación como tarea.

En vez de continuar como simple observadora o víctima del conflicto, la sociedad debe pasar a convertirse en actor de su resolución negociada. Su papel, incluso, puede llevar a salvar la dignidad de los actores y propiciar su encuentro. La paz no es solo asunto del gobierno ( $y$ en eso se equivoca el presidente Santos): es asunto de todos los colombianos.

Medófilo Medina ha dado un paso importante. Hay que continuar la búsqueda.

9 http://www.imtd.org/ Consultado 1 de febrero de 2012 


\section{Referencias}

Atehortúa, A y Rojas, D. (2005). La domesticación de la política internacional y la internacionalización de la política doméstica. Folios. (No. 21) primer semestre 2005. Bogotá: Universidad Pedagógica Nacional, Facultad de Humanidades.

Bobbio, N. (1981). Diccionario de Ciencia Política. México: Siglo XXI Editores.

Duzán, M. (2012). Timochenko, el escritor. Semana, enero 14 de 2012.

Edmead, E. (1971). Analysis and prediction in international mediation. New York: Nitar.

Guevara, E. (1967). Obra Revolucionaria. México: Era.

Mitchell, C. (1997). Evitando daños: Reflexiones sobre la situación de madurez en un conflicto. Estudios Internacionales. Vol. 8, no 15. Guatemala: Recuperado de http://www.gernikagogoratuz.org

Randall, S J. (1992). Aliados y distantes. Bogotá: Tercer Mundo-Ediciones Uniandes.

Reychler, L. (1997). Conflicts en Afrique. Bruselas: GRIP, Nos. 215-217.

Sartori, G. (1994). ¿Qué es la democracia? Bogotá: Altamir Ediciones.

Touraine, A. (1987). El regreso del actor. Buenos Aires: Editorial Universitaria.

Wallerstein, I. (2003). Impensar las Ciencias Sociales. Límites de los paradigmas decimonónicos. México: Siglo XXI.

Zartman, W. (1982). Ripe for resolution: Conflict and intervention in Africa. New York: Oxford University Press.

\section{Documentos}

Carta de Medófilo Medina a Alfonso Cano. Documento en linea, disponible en http://www.razonpublica.com

Carta respuesta de Timoleón Jiménez a Medófilo Medina, Documento en linea, disponible en http://www. razonpublica.com

\section{Prensa e Internet}

Nuevo Siglo Bogotá, enero 15 de 2012

Revista Semana, julio de 2011 y noviembre de 2011 a febrero de 2012.

El Tiempo, julio y noviembre de 2011.

Kien \& Ke, El placer de saber más. http://www.kienyke.com http://www.razonpublica.com

http://www.imtd.org 